\title{
WELLNESS PROGRAM : INTERVENSI PERUBAHAN PARADIGMA KESEHATAN PT KALTIM PRIMA COAL
}

\author{
Febriana Kurniasari \\ Medical Section; Compensation \& Benefits; Human Resources Division \\ PT Kaltim Prima Coal; Sangatta; Kutai Timur
}

\begin{abstract}
ABSTRAK
"Industry 4.0: It's all about the people” Doug Gates, May 2017

Kita berada pada awal revolusi industri 4.0 yang secara fundamental mengubah cara hidup, bekerja dan berhubungan satu sama lain. Menghadapi industri digitalisasi saat ini, rencana pembangunan Indonesia akan mengedepankan optimalisasi Sumber Daya Manusia (SDM). Hal tersebut searah dengan score card dalam strategy map Human Resources Division (HRD) PT Kaltim Prima Coal (KPC), bahwa optimalisasi SDM pada produktivitas dan kegesitan karyawan menjadi salah satu tujuan perusahaan. Salah satu faktor penentu dalam keberhasilan optimalisasi produktivitas karyawan ini adalah dengan kondisi bugar baik secara fisik dan mental. Dari 56 juta kematian di seluruh dunia pada tahun 2015, 40 juta diantaranya disebabkan oleh Noncommunicable Diseases (NCDs) atau penyakit tidak menular. Penyakit yang disebabkan karena gaya hidup tidak baik. KPC sebagai produsen batubara terbesar di Indonesia, memiliki karyawan hingga 4,537 orang. Pengelolaan pelayanan medis kepada karyawan sudah diberikan dengan baik, dari fasilitas hingga rujukan ke luar kota Sangatta, tetapi angka karyawan sakit masih tinggi yaitu sekitar 2,000 orang per tahun. KPC menyadari harus melakukan perubahan paradigma kesehatan kepada karyawan dan tanggungannya, dimana lebih mengutamakan aspek pencegahan penyakit daripada sekedar mengobati. KPC juga mengajak karyawan untuk lebih peduli terhadap kesehatan agar terhindar dari resiko faktor penyakit kronis (NCDs). Dalam makalah ini, penulis membahas Wellness Program yang sedang dilaksanakan KPC dengan metode intervensi berupa berbagai kegiatan promotif dan preventif. Wellness Program merupakan sebuah upaya yang bertujuan lebih kepada peningkatan, pemeliharaan dan perlindungan kesehatan, bukan hanya penyembuhan orang sakit atau pemulihan kesehatan saja. Sebagai dasar dalam pelaksanaan Wellness Program adalah 5 Pilar Kesehatan yang terdiri dari : Mental Sehat, Tidak Merokok, Gerak Fisik atau Olahraga, Diet Seimbang, dan Istirahat Cukup. Perusahaan berharap karyawan dapat bekerja lebih produktif dan sehat hingga masa pensiun. Banyak hal positif yang didapat dengan pelaksanaan Wellness Program. Karyawan dan tanggungannya lebih gemar berolahrga, antusiasme terhadap kegiatan edukatif kesehatan dan semakin tingginya peminat dalam kompetisi berolahraga.
\end{abstract}

Kata Kunci : Sumber Daya Manusia, NCDs, Perubahan Paradigma, Wellness Program

\begin{abstract}
"Industry 4.0 : It's all about the people” Doug Gates, May 2017

We are facing industrial revolution 4.0 which will fundamentally change our lifestyle, working condition and human relation. In the midst of this digitalization era, one of Indonesia's key development goals is to advance human development. This goal is in line with Human Resources Division (HRD) PT Kaltim Prima Coal (KPC) score card in strategic plan to achieve employees' optimum productivity and agility. One of main factors to being successfully able to optimize employees' productivity is by improving health (physically and mentally) and fitness. Globally, in 2015, not less than 40 million deaths (out of total 56 million deaths) are caused by noncommunicable diseases (NCDs). This group of diseases has bad lifestyle as one of its risk factors. KPC as the largest coal mining company in Indonesia currently employs 4,537 individuals in total.
\end{abstract}


Though provision of medical serivices benefit has been delivered well through establishing good health facility and referral to offsite Sangatta, number of work day lost due to illness is still high, but not less than 2,000 in one year. KPC recognizes the need to shift health paradigm of the employees and their dependants, that should be recognized as self-awareness not only as "the absence of illness (medical treatment)". KPC should be able to keep employee care about their health in order to avoid the risk of chronic disease factors (NCDs). The objective of this paper is to describe Wellness Program as an intervention done by KPC to achieve, sustain, and protect health as a complete physical, mental and social wellbeing and not merely the absence of disease or infirmity. Wellness Program is mainly delivered through promotion and prevention campaign. KPC introduces 5 Pillars of Health: Mentally Healthy, Physically Active, Not Smoking, Balanced Diet, and Qualified Rest. The company expects its employees to be more productives and to be healthy even until retiree. Wellness Program has many benefits. Employees and their dependants have become more enthusiastic to participate in physical activity competition and health education sessions.

Keywords: Human Development, NCDs, Shifting Paradigm, Wellness Program

\section{A. PENDAHULUAN}

\section{A.1. Latar Belakang}

Seiring dengan revolusi industri 4.0 dan teknologi digital, persaingan bisnis dan pembangunan yang semula bertumpu pada pemanfaatan sumber daya alam akan bergeser pada penguasaan teknologi informasi dan kompetensi kerja. Investasi sumber daya manusia (SDM) menjadi sangat penting pada masa ini. Sumber daya alam akan habis di eksploitasi namun tidak demikian halnya dengan investasi SDM yang tak terbatas dan terus dinamis (kompasina.com). Oleh karena itu, rencana Anggaran Pendapatan dan Belanja Daerah (APBD) 2020 berfokus pada kualitas SDM, karena SDM bisa menjadi pembuka jalan menuju pertumbuhan ekonomi negara.

Optimalisasi SDM didasari pada pemenuhan kesejahteraan, terutama kesehatan. SDM tidak akan optimal apabila individu rentan terhadap penyakit. Hal yang mendasar menyebabkan kerentanan terjadinya kondisi sakit adalah perilaku pribadi itu sendiri. Semakin sadar akan pentingnya kesehatan, maka penerapan gaya hidup sehat semakin baik, sehingga derajat kesehat semakin meningkat dan semakin tinggi angka harapan hidup di Indonesia. Bagi perusahaan, penerapan gaya hidup yang baik akan berdampak pada meningkatnya produktivitas kerja, karena karyawan yang sehat akan lebih optimal dalam bekerja. Perilaku individu juga bisa ditunjukkan dari cara pandang, pemikiran, menyikapi serta memilih tindakan atas fenomena kesehatan. Apakah kesehatan itu penting atau hanya sekedar tidak sakit saja. Masih banyak orang berperilaku dengan paradigma kesehatan lama yang hanya mementingkan tindakan kuratif atau rehabilitative.

Dalam era industri 4.0 ini membuat segalanya lebih mudah. Karyawan lebih mudah melakukan kegiatan sehari-hari hingga merubah pola hidup mereka. Pada jaman sekarang, hampir semua orang memiliki perangkat handphone. Hal tersebut sangat membantu karyawan dalam melakukan aktifitas tetapi di lain sisi dapat mendorong karyawan lebih malas bergerak. Penyebabnya karena jarang berolahraga dan kurangnya pengetahuan mengenai kesehatan Ditambah lagi istirahat tidak berkualitas serta faktor lainnya yang membuat karyawan lebih sering mengalami sakit sehingga kurang produktif saat bekerja.

KPC adalah perusahaan tambang batu bara yang berlokasi di Sangatta, Kutai Timur, Kalimantan Timur, Indonesia. KPC mengelola salah satu open pit mining terbesar dunia dengan total luas area konsesi pertambangan 84.938 ha dengan kapasitas produksi sebesar 63 juta ton/tahun (Sustainbility Report 2017). Jumlah karyawan KPC adalah 4,573 menurut data tahun 2018. 
Ketidakhadiran karena sakit mencapai 20,796 hari pada tahun 2012, yang artinya 20,796 hari karyawan tidak masuk atau ekuivalen dengan 77 karyawan tidak masuk sepanjang tahun. Dari tahun 2012 sd 2015 hari hilang karena sakit berkurang menjadi 47\% (20,796 hari ke 10,935 hari). Sayangnya jumlah karyawan sakit masih (rata-rata) 2,000 orang setiap tahunnya. Pada periode tersebut, bukan berarti tingkat kesehatan karyawan meningkat, melainkan improve atau perbaikan dari proses administrasi pemberian surat sakit itulah yang sebenarnya membawa dampak signifikan penurunan.

Dari tahun 2009 sd 2018, diketahui karyawan yang meninggal dunia karena sakit mencapai 60 orang. Dimana rata-rata pertahun 6 karyawan meninggal karena sakit. Dari 60 kasus kematian, 38 kasus yang dapat diketahui penyebab kematiannya yaitu 39\% karena kanker, 24\% karena cardiovascular (jantung), $18 \%$ karena diabetes, 5\% karena liver (hati), 5\% karena ginjal, 9\% karena penyakit lain. KPC harus melakukan berbagai upaya perubahan agar jumlah sick leave dan angka kematian karena sakit dapat menurun. Walaupun tidak dipungkiri hal tersebut beriringan dengan semakin tua usia operasional KPC (37 Tahun) dan semakin tua usia karyawan KPC yang menjadi faktor dalam peningkatan jumlah penyakit yang berhubungan dengan faktor usia.

Penyebab terbesar karyawan yang sakit dan meninggal dunia Karena Noncomunicable Diseases (NCDs). NCDs merupakan kelompok penyakit yang tidak disebabkan oleh agen infeksius dan biasanya berkembang dalam waktu lama atau biasa dikenal dengan penyakit tidak menular. Tidak seperti penyakit menular yang penyebabnya terlihat dan bisa dihindari, NCDs disebabkan oleh halhal yang tidak disadari yang akhirnya dapat menyebabkan penyakit. Salah satu contohnya adalah pola makan yang tidak benar dan kurangnya aktivitas fisik. Oleh sebab itu, perusahaan harus melakukan upaya intervensi terhadap perubahan gaya hidup karyawan beserta tanggungannya. Merubah paradigma kesehatan lama menjadi baru. Menekankan pada upaya promotif dan preventif tanpa mengesampingkan upaya kuratif dan rehabilitatif. Oleh sebab itu, perusahaan telah meluncurkan Wellness Program sebagai bentuk aktif dalam meningkatkan kesadaran karyawan akan pentingnya menjaga kesehatan.

\section{A.2. Tujuan}

\section{A.2.1 Karyawan Lebih Produktif}

Di dalam dinamika dunia pertambangan, KPC dihadapkan kepada ketidak pastian. Naik turunnya harga batu bara, daya saing penjualan, hingga perubahan regulasi atau peraturan dari pemerintah mengenai batu bara. Dalam laporan keberlanjutan (Sustainbility Report) 2017 menyebutkan bahwa KPC tetap berkomitmen untuk terus meningkatkan efektifitas, efisiensi, dan produktivitas dalam semua aspek bisnis. Hal ini dilakukan untuk memastikan operasi berjalan dengan baik dan berkelanjutan.

Produktif yang dimaksud adalah karyawan dapat bekerja maksimal secara efisien, efektif sesuai dengan rencana atau tujuan perusahaan. Sedangkan kegesitan adalah bagaimana karyawan memiliki insiatif atau penyelesaian masalah (tugas) dalam menanggapi perubahan situasi. Faktor yang mempengaruhi produktivitas kerja dibagi menjadi dua, yaitu menyangkut kualitas sumber daya manusia (pendidikan, etos kerja, kemampuan fisik/kesehatan) dan sarana pendukung seperti lingkungan kerja, sarana produksi, serta kesejahteraan.

Pada score card strategy map HRD KPC tahun 2016 sd 2021 menyebutkan bahwa "Employee Productivity (produktivitas) and Agility (kegesitan)" adalah salah satu goals (tujuan) dalam mendukung bisnis operasional KPC. Demi mendukung pencapaian tujuan tersebut, salah satu faktor yang berperan penting adalah "Employee \& Familiy Health Maintenance". Bagaimana perusahaan dapat menjaga bahkan meningkatkan kualitas kesehatan karyawan beserta tanggungannya. Indikator kesehatan karyawan bisa dilihat dari angka sick leave, kunjungan sakit baik ke Klinik KPC maupun ke RS/Klinik local Sangatta. 
Kontributor dalam pencapaian kualitas hidup yang baik didasari pada pencapaian banyak hal, salah satunya adalah derajat kesehatan karyawan. Derajat kesehatan karyawan didasari oleh bagaimana kita bisa menghargai arti kesehatan itu sendiri, melalui upaya-upaya aktif seperti kegiatan promotif dan preventif. Apabila karyawan sehat mereka dapat bekerja dengan fokus, mempunyai stamina yang baik, kuat dalam menghadapi perubahan situasi apapun. Apabila karyawan dapat bekerja dengan baik, maka produktivitas akan meningkat, tujuan perusahaan dapat tercapai.

\section{A.2.2 Perubahan Paradigma Kesehatan}

Paradigma sehat merupakan cara pandang, pola pikir, atau model pembangunan kesehatan yang bersifat holistik. Cara pandang ini menekankan pada melihat masalah kesehatan yang dipengaruhi oleh banyak faktor. Upaya perubahan paradigma kesehatan lebih diarahkan pada peningkatan, pemeliharaan dan perlindungan kesehatan. Bukan hanya penyembuhan orang sakit atau pemulihan kesehatan saja. Dengan diterapakan paradigma ini, diharapkan mampu mendorong masyarakat untuk bersikap mandiri dalam menjaga kesehatan mereka sendiri melalui kesadaran yang lebih tinggi akan pentingnya pelayanan kesehatan yang bersifat promotif dan preventif. (Hudaya, Isna. 2010)

KPC dengan Wellness Program adalah suatu "paradigma baru" dalam pembangunan kesehatan di Indonesia. Sebuah program terobosan dengan menitik beratkan pada upaya-upaya bersifat promotif dan preventif dengan tujuan dapat merubah paradigma kesehatan itu sendiri. Mudahnya akses data dan semakin kayanya ilmu pengetahuan dengan informasi faktor penyebab penyakit dapat merubah pemahaman tentang konsep sehat dan sakit. Hal tersebut dapat menggugurkan paradigma pembangunan kesehatan lama yang mengutamakan pelayanan kesehatan bersifat kuratif dan rehabilitatif. Pembangunan kesehatan dalam jangka panjang mampu mendorong karyawan beserta tanggungannya untuk bersikap mandiri dalam menjaga kesehatan.

\section{A.3 Metode Pemecahan Masalah : Wellness Program}

Teori Klasik H. L. Bloom menyatakan bahwa ada 4 faktor yang mempengaruhi kesehatan yaitu gaya hidup, lingkungan, pelayanan kesehatan dan faktor genetik. Sedangkan Undang-Undang Kesehatan No.36 tahun 2009 memberikan batasan : Kesehatan adalah keadaan sehat baik secara fisik, mental, spiritual maupun sosial yang memungkinkan setiap orang untuk hidup produktif secara sosial dan ekonomi. Maka setiap manusia apabila ingin berproduktif maka diperlukan jiwa dan fisik yang sehat.

Sebagai bentuk komitmen KPC terhadap kesehatan karyawan dan tanggungannya, Maret 2018 pada saat ulang tahun KPC, lewat pidato Kepala Teknik Tambang (KTT), KPC telah menggaungkan 5 Pilar Kesehatan. Wellness Program merupakan perwujudan dari upaya mewujudkan 5 Pilar Kesehatan dalam lingkungan kerja. 5 Pilar terdiri dari :

1. Mental yang sehat

2. Gerak fisik / olahraga

3. Tidak merokok

4. Diet seimbang

5. Istirahat yang cukup

Intervensi Wellness sesuai dengan bagan di atas bertujuan untuk mendorong karyawan melakukan perubahan perilaku melalui pendekatan populasi dan kelompok beresiko. Kegiatan itu dilakukan melalui promosi kesehatan, kompetisi, edukasi publik, dll yang di evaluasi melalui screening rutin tahunan yaitu medical check up. Tujuan utama dalam program ini meningkatkan produktivitas karyawan dan menekan angka ketidak hadiran karena sakit. Dalam upaya peningkatan produktivitas karyawan tersebut maka proporsi karyawan yang termasuk dalam kelompok beresiko perlu di turunkan. Kelompok karyawan beresiko tersebut perlu diberi pengetahuan tentang perubahan gaya hidup sehat. Akan tetapi perubahan tersebut tidak hanya diperlukan untuk yang sudah beresiko tetapi juga yang sehat. 


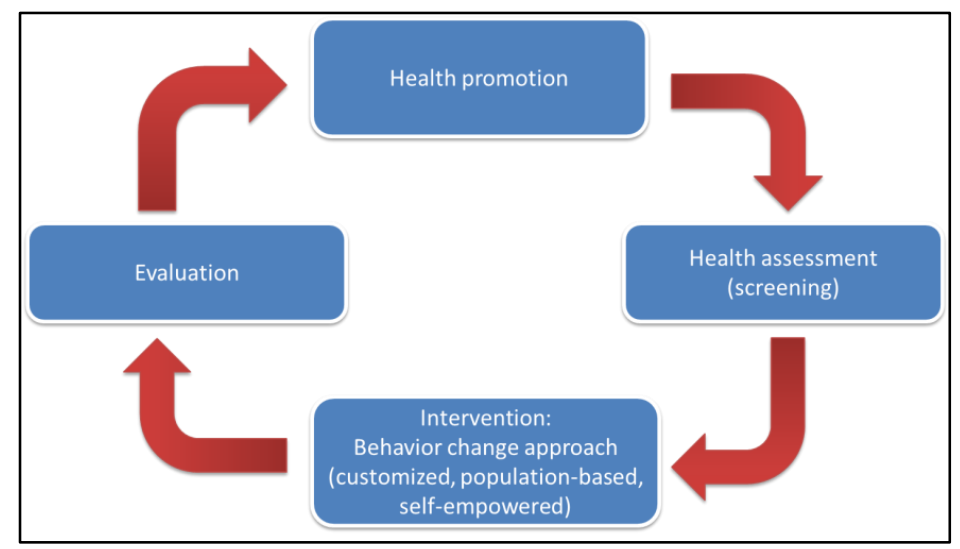

Gambar 1. Bagan Kegiatan Wellness Program

\section{B. METODOLOGI PENELITIAN}

Studi ini dilakukan dengan mengumpulkan data primer dan sekunder terkait intervensi Wellness Program sebagai berikut:

a. Data Primer : data-data MCU (Medical Check Up) tahunan karyawan, data sick leave (hari hilang karena sakit), dan populasi karyawan KPC.

b. Data Sekunder : KSDM (Kebijakan Sumber Daya Manusia) 53 tentang Program Kebugaran Karyawan, kumpulan informasi mengenai penyakit tidak menular dan kumpulan informasi mengenai kesehatan serta upaya promotif dan preventif.

Analisis data

Pengolahan dilakukan secara kuantitatif deskriptif dan kualitatif terhadap data primer dan sekunder. Data primer dimaksud sesuai dengan data pada kunjungan klinik dan/atau rujukan lainnya.

\section{HASIL DAN PEMBAHASAN}

\section{C.1. Data Awal}

Populasi Karyawan KPC (2018)

Gambar 2 berikut adalah diagram populasi karyawan KPC pada tahun 2018 :

\section{KPC EMPLOYEE AGE DISTRIBUTION 2018}

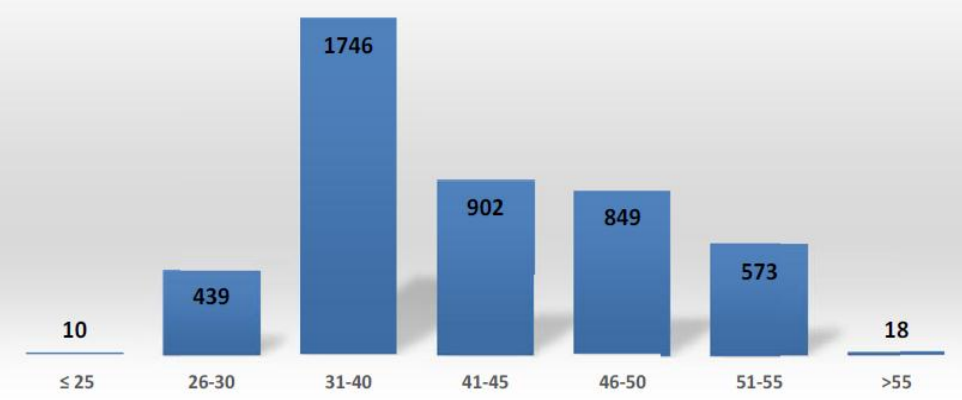

Gambar 2. Persebaran Populasi Sesuai Umur 
Menurut kelompok umur proporsi usia karyawan KPC saat ini berada pada kelompok 31 - 40 tahun. Rerata usia karyawan KPC menurut data 2018 adalah 41 tahun. Dengan demikian tidak heran sudah banyak penyakit kronis muncul karena populasi yang menua.

\section{C.2 Faktor Resiko Penyakit Kronis Karywan KPC}

Tiga besar faktor penyebab kematian di KPC (2009 sd 2018) adalah $39 \%$ penyakit kanker, $24 \%$ cardiovascular (penyakit jantung) dan $18 \%$ penyakit diabetes.

a. Kanker

Kanker disebabkan oleh pertumbuhan sel yang tidak terkontrol. Pertumbuhan sel yang tidak normal ini awalnya terjadi di bagian tubuh tertentu dan dapat menyebar ke bagian tubuh lain, bahkan dapat menghancurkan jaringan tubuh normal. Salah satu penyebab kanker bisa dipengaruhi oleh faktor lingkungan seperti virus, paparan zat kimia secara berlebih, hingga kebiasaan merokok.

Tren 2012 sd 2018 menyebutkan bahwa populasi karyawan merokok di KPC mulai berkurang, tetapi, usaha preventif dan promotif terhadap bahaya merokok masih dilaksanakan (pilar ke-3 : tidak merokok). Hal ini bertujuan agar populasi karyawan merokok semakin berkurang sehingga faktor resiko penyakit kanker dapat berkurang juga.

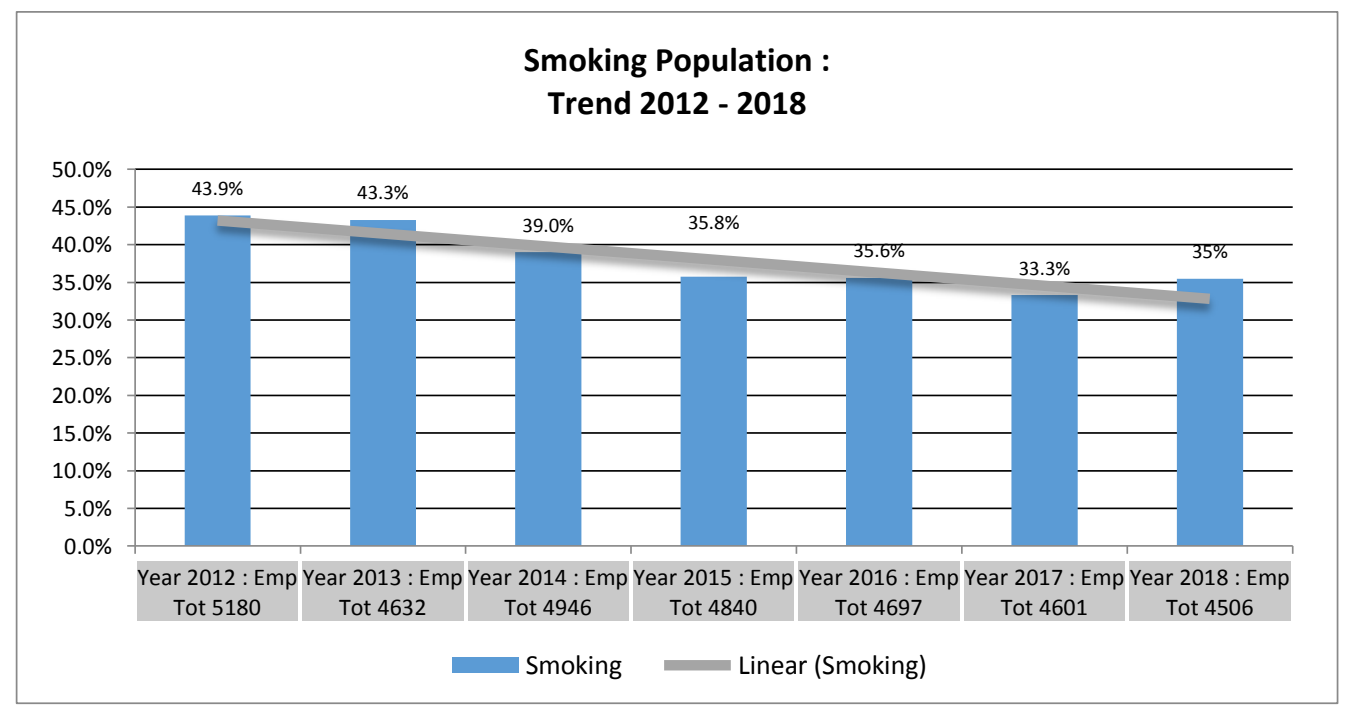

Gambar 3. Diagram Tren Populasi Karyawan Merokok 2012 - 2018

b. Cardiovascular (Penyakit Jantung)

Sama hal nya dengan penyakit kanker, penyakit jantung disebabkan karena banyak faktor seperti kadar lipid dalam darah meningkat (hiperlipidiemia) atau lebih dikenal dengan kolestrol tinggi, kebiasan merokok, tekanan darah tinggi (hipertensi) serta kegemukan (overweight atau obesitas).

Adapun kolestrol dibagi menjadi dua jenis yaitu kolestrol baik (HDL/High Density Lipoprotein) dan kolestrol jahat (Low Density Lipoprotein/LDL). Kolestrol menjadi masalah apabila LDL terlalu tinggi dan HDL terlalu rendah. Biasanya, karyawan dengan hiperlipidemia memiliki kadar LDL dan trigliserida tinggi. Sehingga menyebabkan sumbatan atau plak pada dinding pembuluh darah. Lambat laun plak tersebut akan meluas dan menyumbat arteri sehingga dapat menyebabkan penyakit jantung dan/atau stroke.. 


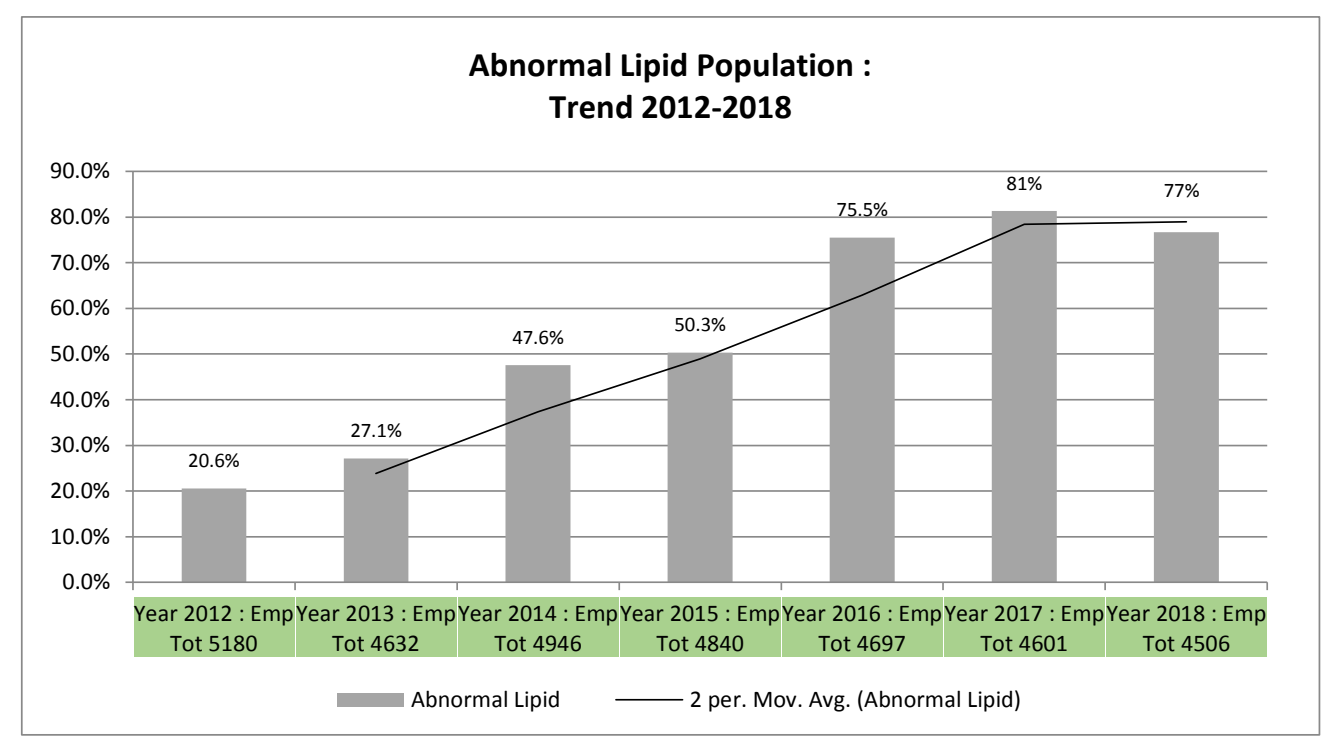

Gambar 4. Diagram Tren Populasi Karyawan dengan Abnormal Lipid

Faktor resiko penyakit jantung lainnya adalah masalah kegemukan. Populasi karyawan KPC dengan overweight atau obesitas menunjukkan peningkatan. oleh sebab itu, KPC gencar melakukan promosi dan pencegahan penyakit jantung karena faktor kegemukan. Baik dari kompetisi olahraga, senam, hingga lomba penurunan berat badan/Ideal Weight Challege yang sudah dilaksanakan hingga batch 2.

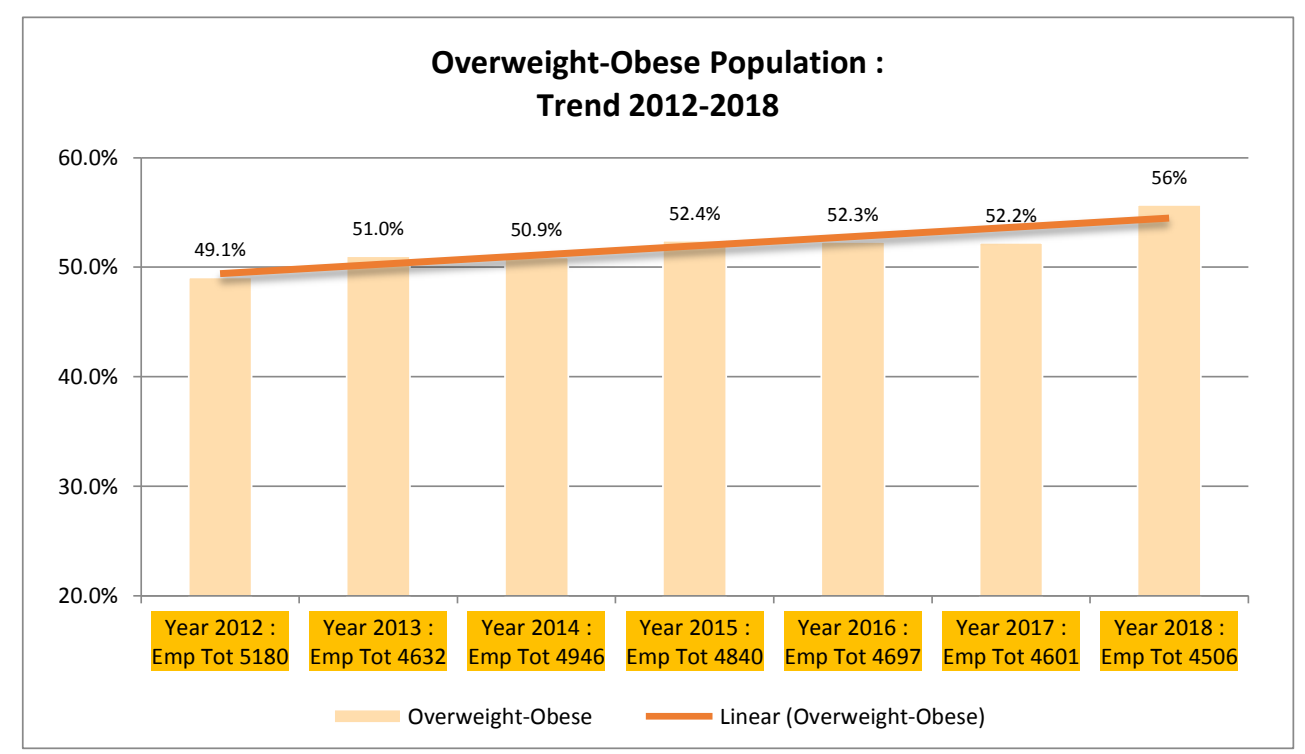

Gambar 5. Diagram Tren Populasi Karyawan Overweight - Obesitas

c. Diabetes (kelebihan kadar gula dalam darah)

Penyakit diabetes ditandai dengan kadar gula (glukosa) darah tinggi atau diatas normal. Tren menunjukkan semakin tingginya karyawan terkena diabetes dan prediabetes. Prediabetes adalah kondisi dimana saat kadar gula dalam darah sudah mendekati ambang batas diabetes. Dari diagram dibawah diketahui bahwa angka karyawan KPC yang terkena diabetes dan prediabetes adalah 23,3\% hal itu sinergi dengan data dari Riset Kesehatan Dasar (Riskesdas) tahun 2018, dimana Kaltim menduduki peringkat ke-2 tertinggi se Indonesia untuk kategori penderita diabetes (usia $\geq 15$ tahun). 


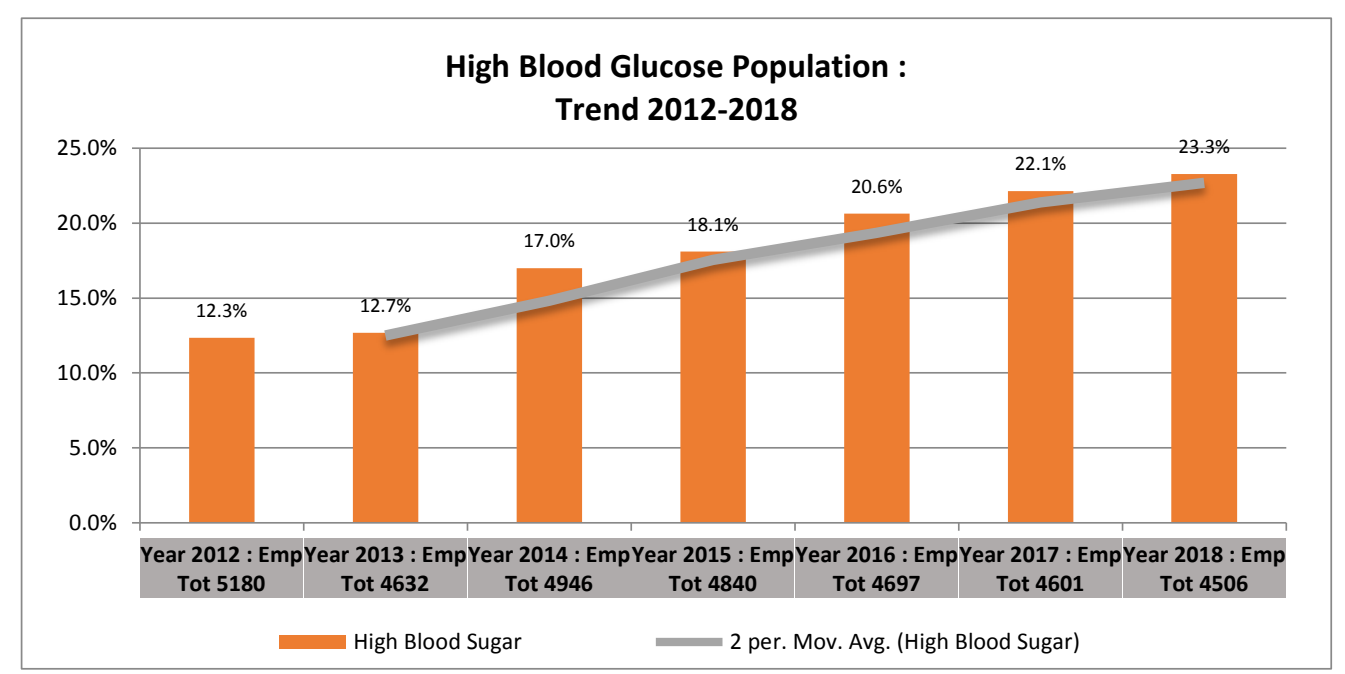

Gambar 6. Diagram Tren Karyawan Kadar Gula Darah Diatas Normal

Bagi karyawan dengan penyakit diabetes diharapkan tahu dan selalu memilih makanan sehat, karena ini sudah menjadi perawatan selain rutin meminum obat, serta melakukan olahraga. American Diabetes Association merekomendasikan agar setiap orang, terlebih orang dengan diabtes, tetap aktif bergerak dan berolahraga.

\section{C.3 Sick Leave (Ketidakhadiran Karyawan Karena Sakit)}

Ketidakhadiran di tempat kerja salah satunya didapat dari surat sick leave yang dapat berpengaruh terhadap produktivitas karyawan. Apabila melihat diagram tren diatas, dari tahun 2012 sd 2015, sick leave turun cukup drastis hingga 47\%. Tetapi memasuki tahun 2016 hingga tahun 2018 mengalami kenaikan. Angka karyawan yang mendapat surat sakit pun berkisar 2,000 orang. Artinya, karyawan masih banyak mengalami sakit. Intervensi Perusahaan terhadap perubahan perilaku kesehatan karyawan ditingkatkan. Bertujuan agar angka ketidakhadiran karena sakit dapat berkurang, produktivitas karyawan dapat meningkat.

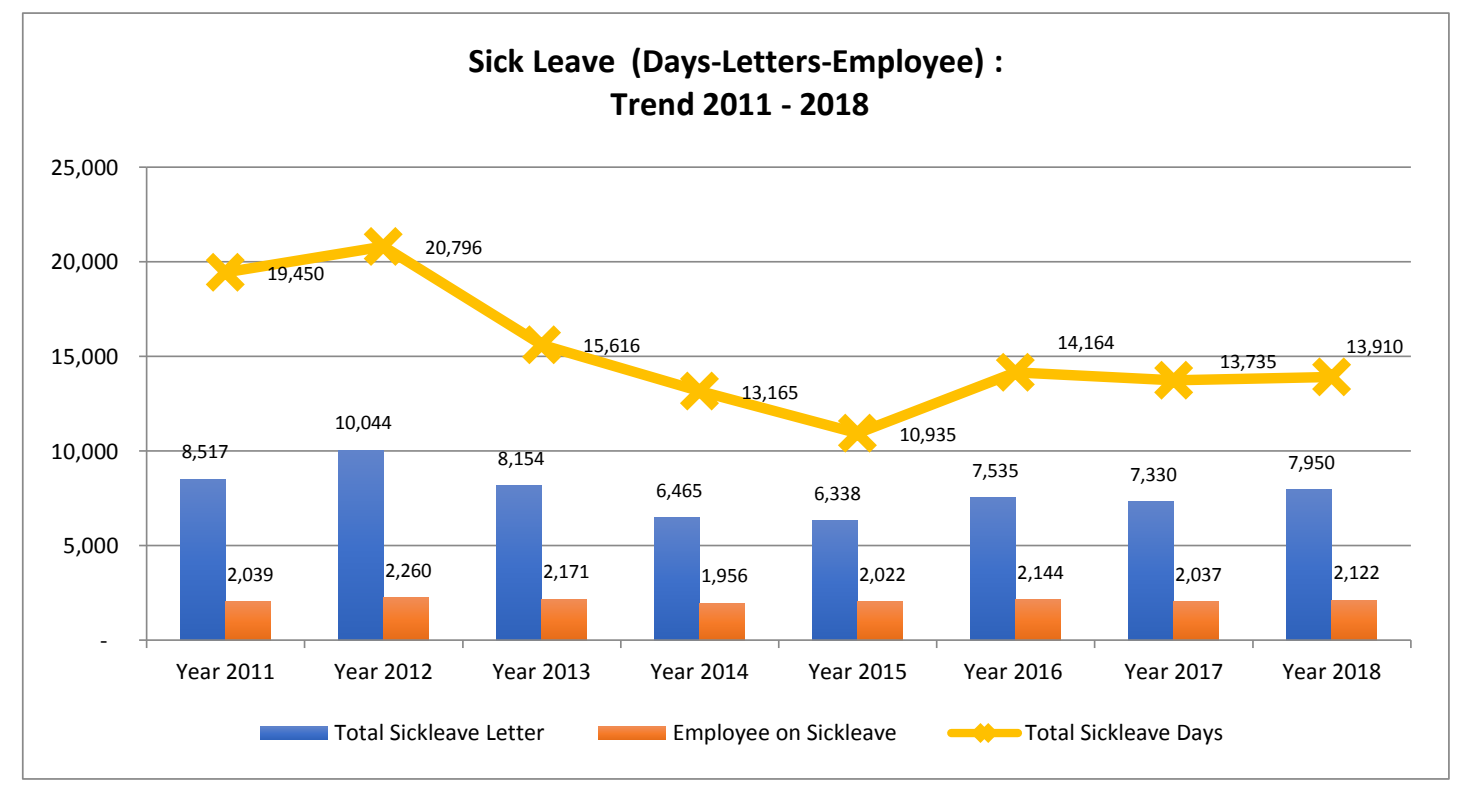

Gambar 7. Tren Karaywan Tidak Masuk karena Sakit (Sick Leave) 2011 - 2018 


\section{C.4 Strategi Wellness Program (intervensi) \\ C.4.1 Pendekatan Populasi}

Pendekatan populasi yang dimaksud adalah kepada semua populasi baik yang terkena resiko atau tidak, baik yang sudah memiliki gejala sakit maupun belum.

\section{C.4.2 Pendekatan Kelompok Resiko Tinggi}

Pendekatan kelompok resiko tinggi dilakukan kepada populasi yang diketahui telah memiliki faktor resiko terhadap penyakit. Faktor resiko yang dimaksud dikuantifikasi sesuai dengan skor Kumulatif Indikator Wellness (Score Cumulative of Wellness Indicator) seperti tertuang dalam tabel di bawah ini.

Tabel 1. Skor Indikator Wellness

\begin{tabular}{|c|c|c|c|c|c|c|c|c|c|c|c|c|}
\hline Parameter & BMI & $\begin{array}{l}\text { SKOR } \\
\text { A }\end{array}$ & Glucose & $\begin{array}{l}\text { SKOR } \\
B\end{array}$ & LDL & $\begin{array}{l}\text { SKOR } \\
\text { C }\end{array}$ & BP sys & $\begin{array}{l}\text { SKOR } \\
D\end{array}$ & BP dias & $\begin{array}{l}\text { SKOR } \\
\mathrm{E}\end{array}$ & Smoking & $\begin{array}{l}\text { SKOR } \\
\mathrm{F}\end{array}$ \\
\hline Medium & $>25-29$ & 1 & $120-140$ & 1 & $115-120$ & 1 & $130-140$ & 1 & $85-90$ & 1 & YES & 3 \\
\hline High & $>29-33$ & 2 & $>140-160$ & 3 & $>120-150$ & 3 & $>140-160$ & 3 & $>90-100$ & 3 & No & 0 \\
\hline \multirow[t]{2}{*}{ Very High } & $>33-35$ & 3 & $>160$ & 7 & $>150$ & 4 & $>160$ & 7 & $>100$ & 7 & & \\
\hline & $>35$ & 7 & & & & & & & & & & \\
\hline
\end{tabular}

Sumber : Kebijakan HRMP No. 53 - Program Kebugaran Perusahaan

Skor kumulatif dihitung dengan menambahkan jumlah skor di masing-masing parameter yang sesuai, ditambah dengan jumlah parameter yang abnormal / score cumulative calculated by adding the number of scores in each of appropriate parameters, coupled with the number of parameters were abnormal

Berdasarkan data Annual MCU 2018 karyawan diketahui bahwa 11\% hipertensi, $23 \%$ diabetes dan prediabetes, $35 \%$ perokok aktif dan $56 \%$ overweight-obesitas. Hasil dari skoring tersebut diatas terdapat populasi Low Risk (resiko rendah) 460 orang, 3,589 Middle Risk (resiko sedang) dan 465 High Risk (resiko tinggi). Pengelompokan kelompok resiko tinggi ini mempermudah dalam penyusuanan strategi kegiatan Wellness Program.

\section{C.5. Intervensi Wellness Program}

Sebagai bentuk komitmen KPC terhdap Wellness Program, mulai maret 2019, KPC melewati HRD merekrut satu occupational health doctor, satu health educator (dokter) dan dua paramedic. Tim tersebut bertugas khusus dalam melaksanakan Wellness Program. Adapun Wellness Program yang telah dilaksanakan adalah sebagai berikut :

Tabel 2. Daftar Kegiatan Wellness Program 2018 sd 2019

\begin{tabular}{clcc}
\hline No & \multicolumn{1}{c}{ Program } & Frekuensi & Keterangan \\
\hline 1 & $\begin{array}{l}\text { Radio Talk } \\
\text { Dua minggu sekali dan siaran ualang sebanyak dua kali }\end{array}$ & 80 sesi & $\begin{array}{c}\text { Seluruh karyawan, } \\
\text { tanggungan, kontraktor } \\
\text { dan masyarakat }\end{array}$ \\
2 & $\begin{array}{l}\text { Artikel Kesahatan (Email Broadcast) } \\
\text { Poster : "No Smoking", "Healthy Diet", "Kesehatan }\end{array}$ & \pm 5 topik & $\begin{array}{c}\text { Seluruh karyawan } \\
\text { Seluruh karyawan di } \\
\text { departemen tersebut }\end{array}$ \\
& $\begin{array}{l}\text { Mental", "Gerak Fisik" dll. } \\
\text { Disetiap departemen/divisi/gedung kantor. } \\
\text { Banners: "No Smoking", "Healthy Diet", "Kesehatan } \\
\text { Mental", "Gerak Fisik" dll } \\
\text { Dijalan utama baik jalan umum atau didalam area } \\
\text { kerja KPC }\end{array}$ & $>15$ & $\begin{array}{c}\text { Seluruh karyawan, } \\
\text { tanggungan, kontraktor } \\
\text { dan masyarakat }\end{array}$ \\
\hline
\end{tabular}




\begin{tabular}{|c|c|c|c|}
\hline No & Program & Frekuensi & Keterangan \\
\hline 5 & $\begin{array}{l}\text { Seminar / Pelatihan : } \\
\text { - Sport Medicine } \\
\text { On } 21 \text { Mar } 2018 \text { in Serbaguna Building Bukit } \\
\text { Pelangi } \\
\text { - "Penyakit Datang dari Hati” } \\
\text { oleh Dr. Agus Ali Fauzi PGD. Pall. Med (ECU) } \\
\text { 1 Desember } 2018 \\
\text { - Seminar Pembekalan Ideal Weught Challenge Batch } \\
2 \\
\text { Desember } 2018 \\
\text { - Seminar "Saya Peduli Hepatitis" oleh Dr. RR. } \\
\text { Ignatius Sinta Murti, Sp.PD-KGEH } \\
\text { 14 - } 15 \text { Agustus 2019 } \\
\text { - BLS (Basic Life Support) Training kepada dependen } \\
\text { (istri karyawan) yang mempunyai faktor resiko } \\
\text { April } 2019\end{array}$ & 3 Sesi & $\begin{array}{l} \pm 300 \text { karyawan dan } \\
\text { keluarga } \\
\pm 441 \text { karyawan dan } \\
\text { keluarga } \\
\pm 300\end{array}$ \\
\hline 6 & $\begin{array}{l}\text { Focused Group Discussion by External Speaker : } \\
\text { Terapi Nutrisi kepada Karyawan dengan Faktor Resiko } \\
\text { Penyakit Kronis } \\
\text { 3-4 Mei } 2018 \text { oleh Dr. Inrawaty, SP. GK, M.Kes }\end{array}$ & 6 group & $\begin{array}{l}131 \text { karyawan dan } \\
\text { tanggungan }\end{array}$ \\
\hline 7 & $\begin{array}{l}\text { Focused Group Discussion by KPC Wellness team : } \\
\text { Bagi karyawan beresiko penyakit kronis seperti diabetes } \\
\text { Juli sd September } 2019\end{array}$ & 7 kali & 16 karyawan \\
\hline 8 & $\begin{array}{l}\text { Health Talk by KPC Wellness Team : } \\
\text { Disetiap area kerja (masing-masing departermen atau } \\
\text { divisi) dengan berbagai 682opic kesehatan } \\
\text { April sd Agustus } 2019\end{array}$ & 16 kali & \pm 883 karyawan \\
\hline 9 & $\begin{array}{l}\text { Home Visit } \\
\text { Pendeketan kepada karyawan yang bermasalah dengan } \\
\text { kesehatan }\end{array}$ & 5 kali & 3 orang beserta keluarga \\
\hline \multirow[t]{2}{*}{10} & $\begin{array}{l}\text { Aerobic Exercises: } \\
\text { "Sabtu Kita Senam" } \\
\text { Setiap sabtu pagi di jogging track Swarga bara Town } \\
\text { Hall. } \\
\text { - "Senam di Temnat Keria" }\end{array}$ & 80 sesi & $\begin{array}{l}\text { 150-300 karyawan dan } \\
\text { keluar setiap kali senam }\end{array}$ \\
\hline & $\begin{array}{l}\text { Dilaksanakn secara regular seminggu sekali di setiap } \\
\text { area kerja masing-masing departemen (11 Point). } \\
\text { Jalan Sehat } \\
\text { - Jalan Sehat HUT KPC ke-36 }(7 \mathrm{~km}) \\
7 \text { Juli } 2018 \text { in Swarga Bara hingga area kerja KPC. } \\
\text { - Jalan Sehat HUT KPC ke-37 } 4 \text { km) } \\
4 \text { Mei } 2019 \text { di area Swarga Bara hingga area kerja } \\
\text { KPC. }\end{array}$ & $>600$ sesi & $\begin{array}{l}\text { 30-50 karyawan sekali } \\
\text { senam }\end{array}$ \\
\hline \multirow[t]{3}{*}{11} & $\begin{array}{l}\text { Table Tennis Tournaments: } \\
\text { - Departments in Mine Site Office }\end{array}$ & 1 turnamen & 64 karyawan $(16$ tim) \\
\hline & $\begin{array}{l}\text { On Dec } 2017 \text { - Jan } 2018 \text { in M4 Building } \\
\text { - HR Division } \\
\text { On Feb-Mar } 2018 \text { in M4 Building }\end{array}$ & $\begin{array}{l}1 \text { turnamen } \\
1 \text { turnamen } \\
1 \text { turnamen }\end{array}$ & 24 karyawan (12 tim) \\
\hline & $\begin{array}{l}\text { - KPC Departments/Divisions } \\
\text { On Jul-Aug } 2018 \text { in M4 Building } \\
\text { - Mining Support Division } \\
\text { On Sep-Oct } 2018 \text { in M4 Building }\end{array}$ & & $\begin{array}{l}164 \text { karyawan (38 tim) } \\
111 \text { karyawan (37 tim) }\end{array}$ \\
\hline 12 & $\begin{array}{l}\text { Badminton Tournament: CPP Cup } \\
\text { On Nov } 2018 \text { - Jan } 2019\end{array}$ & 1 turnamen & 60 karyawan \\
\hline 13 & KPC Marching Competition & 1 batch & 398 karyawan \\
\hline
\end{tabular}




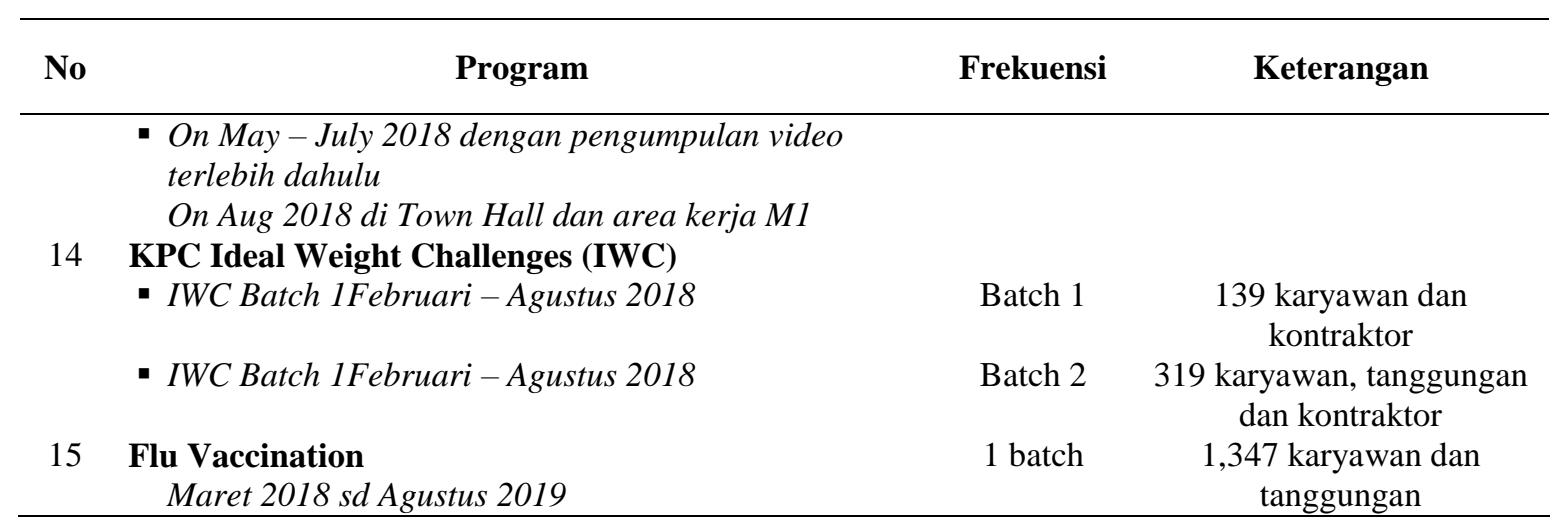

\section{C.6 Pendekatan Populasi}

C.6.1 Edukasi Kesehatan / Pencegahan Penyakit (Seminar, Health Talk, Radio Talk, Olahraga)

- Partisipan dalam kegiatan seminar kesehatan semakin meningkat. Kegiatan seminar ditujukan kepada karyawan dan/atau dependen dengan faktor resiko penyakit kronis (sasaran) serta untuk umum baik karyawan tidak beresiko atau kader kesehatan (masyarakat).

- Antusiasme peserta semakin baik dengan adanya interaksi tanya jawab dan diskusi serta kuis yang diadakan selama seminar.

- Salah satu seminar yang telah diadakan menjalankan "Pre and Post Test" dan hasil menunjukkan bahwa nilai post test lebih baik dari pre test. Hal tersebut menunjukkan bahwa edukasi atau ilmu yang disampaikan pembicara dapat diterima oleh peserta.

- Health Talk yang sedang dilaksanakan oleh Tim Wellness mendapatkan respon positif. Banyak departemen meminta agar dilaksanakan Health Talk rutin di area kerja masingmasing secara rutin.

- Radio Talk dilakukan secara terjadwal dan bekerjasama dengan Radio Gema Wana Prima (GWP) setiap hari rabu (2 kali siaran langsung dan 2 kali siaran tunda setiap bulannya) pkl 16.00 sd 16.00 WITA. Radio Talk merupakan media komunikasi yang efektif karena dapat menjangkau daerah lebih jauh (hingga Bontang dan sebagian Samarinda). Telah rutin dilaksanakan dari tahun 2018 dengan berbagai topik atau issue seputar kesehatan. Promosi kesehatan ini juga menjadi salah satu bentuk komitmen KPC kepada masyarakat karena dapat menjangkau lebih banyak populasi.

- Kegiatan rutin senam seperti SKS (Sabtu Kita Senam) dan senam di area kerja masingmasing baik di wilayah kantor non operational (support division) seperti gedung Mine Site (M1) hingga divisi operasional seperti Mining Operation Division (MOD), Mining Support Division (MSD), Coal Procesing Handling Division (CPHD) dll. Hal tersebut menunjukkan bahwa kesadaran akan gerak fisik dirasakan oleh banyak karyawan.

\section{C.6.2 Pendekatan Resiko Tinggi}

- Ideal Weight Challenge (IWC)

Ideal Weight Challenge dilaksanakan sebagai bentuk penurunan angka populasi karyawan overweight dan obesitas. Sasaran dalam program ini tidak hanya karyawan KPC saja tetapi kekeluarga, bahkan kontraktor pun banyak yang antusias dalam program ini. IWC berhasil menurunkan populasi obesitas di KPC sebesar $9 \%$ (3\% menjadi Ideal, 6\% menjadi overweight). Program ini akan terus dilakukan sebagai "trigger" karyawan dan tanggungannya dapat memasuki Body Mass Index (BMI) normal.

- Ideal Weight Challenge Batch 1 mencakup penurunan Body Mass Index (BMI) dengan bobot 60\% dan penurunan Lingkar Perut (LP) dengan bobot 40\%. Para peserta melakukan 6 kali penimbangan dan pengurkuran dari Februari sd Agustus 2018. Hasil dari kegiatan IWC Batch 1 adalah sebagai berikut : 
Jumlah pendaftar 139 orang (KPC dan kontraktor) dan yang berhasil melakukan penimbagan serta pengukuran akhir adalah 72 orang.

$\checkmark 79$ peserta dengan kriteria obesitas, 20 orang telah berhasil masuk ke zona overweight dan 2 orang masuk ke BMI normal.

$\checkmark 41$ peserta dengan kriteria overweight, 8 orang yang berhasil masuk ke BMI normal.

- Ideal Weight Challenge Batch 2 mencakup penurunan Body Mass Index (BMI) dengan bobot $80 \%$ dan penurunan Lingkar Perut (LP) dengan bobot 20\%. Para peserta melakukan 6 kali penimbangan dan pengurkuran dari Januari sd Juli 2019. Hasil dari kegiatan IWC Batch 2 adalah sebagai berikut :

$\checkmark$ Jumlah pendaftar 319 orang (KPC, depdenden dan kontraktor) dan yang berhasil melakukan penimbangan serta pengukuran hingga akhir adalah 170 orang.

$\checkmark 145$ peserta dengan kriteria obesitas, 39 orang berhasil masuk ke zona overweight dan 1 orang masuk ke BMI normal.

$\checkmark 75$ peserta dengan kriteria overweight, 14 orang masuk ke zona BMI normal

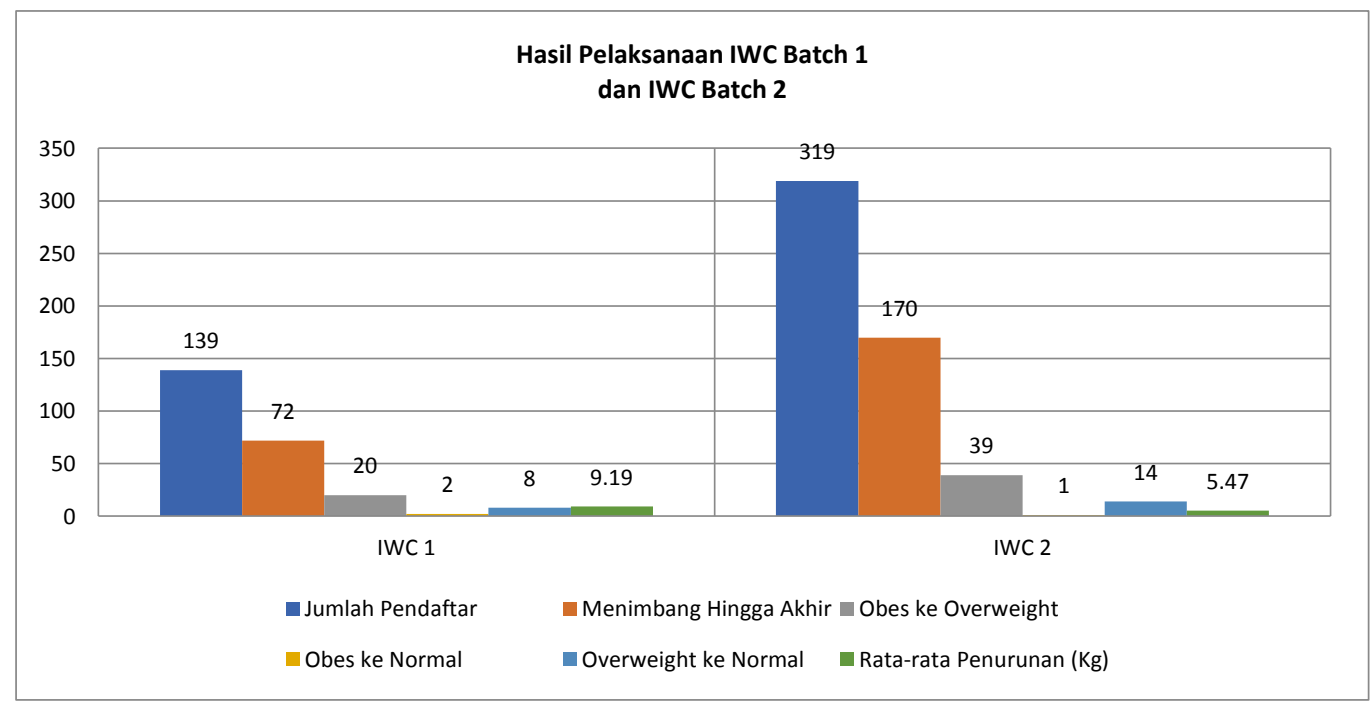

Gambar 8. Hasil Pelaksanaan IWC Batch 1 dan IWC Batch 2

\section{SIMPULAN}

Tidak hanya berhenti disini saja, Wellness Program akan terus dilaksanakan secara berkelanjutan. Peran aktif karyawan dan tanggungannya serta dukungan dari KPC sangat diperlukan demi kesuksesan program ini. Hasil program ini tidak semuanya bisa dirasakan dalam waktu yang instan, mungkin akan dirasakan di lain waktu. Bukan hanya KPC saja yang akan menuai hasilnya, terlebih karyawan dan keluarga akan mendapatkan dampak baik dalam program ini.

Wellness Program yang sedang dijalankan mendapatkan respon positif dari berbagai pihak, mulai dari Management KPC, karyawan dan tanggungannya, kontraktor hingga masyarakat. Wellness Program adalah proses aktif yang mengajak seluruh karyawan dan tanggungannya untuk menjadi sadar dan mampu membuat pilihan menuju hidup yang lebih sehat dan berarti. Bukan hanya sekedar berarti tidak sakit, tetapi merupakan sebuah proses perubahan perilaku. Dengan intervensi paradigm baru ini, mampu mendorong karyawan untuk bersikap mandiri dalam menjaga kesehatan, dapat meningkatkan kualitas hidup, lebih produktif dalam bekerja dan sehat hingga pensiun. "KPC Wellness... Sehat, Semangat, Produktif !!!” 


\section{DAFTAR PUSTAKA}

HRMP 53 - Program Kebugaran Perusahaan

Sustainbility Report PT Kaltim Prima Coal 2017

Hasil Riskesdas 2018

Info seputar SDM Indonsia diambil dari https://www.liputan6.com/bisnis/read/4039466/jokowiapbn-2020-fokus-pada-kualitas-sdm. Diunduh pada 4 September 2019

Info seputar industry 4.0 diambil dari . https://www.zenius.net/blog/21104/revolusi-industri-4-0. Diunduh pada 4 September 2019.

Info seputar industry 4.0 diambil dari https://www2.deloitte.com/content/dam/Deloitte/tr/Documents/manufacturing/Industry40_Are-you-ready_Report.pdf. Diunduh pada 4 September 2019.

Info seputar gizi seimbang diambil dari http://www.depkes.go.id/article/view/17103100004/sehatberawal-dari-piring-makanku.html. Diunduh pada 5 Spetember 2019.

Informasi seputar kanker diambil dari https://www.alodokter.com/mengenal-mutasi-gen-penyebabkanker Diunduh pada 5 September 2019.

Info seputar rokok diambil dari . https://hellosehat.com/hidup-sehat/berhenti-merokok/bahayamerokok-pada-daya-tahan-tubuh/. Diunduh pada 5 September 2019.

Faktor berpengaruh terhadap produktivitas karyawan di ambil https://bizfluent.com/info-10000291factors-affect-productivity.html. Diunduh pada 6 September 2019.

Paradigma kesehatan diambil dari makalah (situs internet)

https://www.academia.edu/10354820/Konsep_Paradigma_Sehat_dan_Sejarah_Perkembanga n_Promosi_Kesehatan Diunduh pada 7 September 2019. 
PROSIDING TPT XXVIII PERHAPI 2019

\section{6}

